\title{
Artigo Original / Original Paper \\ Caracterização morfoanatômica, fitoquímica e histoquímica de Hymenaea courbaril (Leguminosae), ocorrente na Amazônia Meridional
}

\author{
Morpho-anatomical, Phytochemical, and Histochemical characterization \\ of Hymenaea courbaril (Leguminosae), occurring in Southern Amazon
}

\author{
Poliana Vicente Tiago ${ }^{1}$, Diene Larocca ${ }^{2}$, Ivone Vieira da Silva ${ }^{2}$, Adriano Aynes Carpejani ${ }^{1}$, \\ Auana Vicente Tiago ${ }^{1}$, Juliana de Freitas Encinas Dardengo ${ }^{1,3,4}$ \& Ana Aparecida Bandini Rossi ${ }^{1}$
}

\begin{abstract}
Resumo
Este estudo objetivou caracterizar a morfoanatomia, histoquímica e fitoquímica dos órgãos vegetativos de Hymenea courbaril, visando detectar estruturas secretoras ou células secretoras que armazenam metabólitos secundários, cujas atribuições conferem potencial medicinal à espécie. A coleta do material vegetal foi realizada em indivíduos nativos de H. courbaril no município de Alta Floresta, MT. O material botânico (folíolos e caule) foi fixado, foram realizadas secções transversais e paradérmicas nos órgãos, montadas em lâminas histológicas e o material fresco foi submetido a testes histoquímicos e fitoquímicos. Foram detectados canais de secreção no folíolo e caule de $H$. courbaril, a caracterização fito-histoquímica deu positivo para metabólitos secundários como taninos, esteroides, flavonoides, compostos fenólicos, lipídios, saponinas e glicosídeos, a presença destes compostos pode conferir à espécie atividades biológicas importantes no tratamento de diversos tipos de doenças. Além disso, tais substâncias desempenham um importante papel ecológico de manutenção e continuidade da espécie na natureza, como mecanismos contra a herbivoria e a desidratação.
\end{abstract}

Palavras-chave: cavidade secretora, jatobá, medicinal.

\begin{abstract}
This study aimed to characterize the morphology, histochemistry and phytochemistry of the vegetative organs of Hymenaea courbaril, aiming to detect secretory structures and secretory cells that store secondary metabolites, whose attributions confer medicinal potential to the species. The collection of plant material was carried out in native individuals of $H$. courbaril in the municipality of Alta Floresta, MT. The plant material (leaflets and stem) was fixed, transverse and paradermic sections were performed on the organs, mounted on histological slides, and the fresh material was submitted to histochemical and phytochemical tests. Secretion channels were detected in the leaflet and stem of $H$. courbaril, the phyto-histochemical characterization proved positive for secondary metabolites such as tannins, steroids, flavonoids, phenolic compounds, lipids, saponins and glycosides, the presence of these compounds may confer important biological activities in the treatment of various types of diseases. In addition, such substances present an important ecological role in the maintenance and continuity of the species in nature as mechanisms against herbivory and dehydration.
\end{abstract} Key words: secretory cavity, jatobá, medicinal.

\footnotetext{
${ }^{1}$ Universidade do Estado de Mato Grosso, Faculdade de Ciências Biológicas e Agrárias, Lab. Genética Vegetal e Biologia Molecular, Rede Bionorte, Campus de Alta Floresta, Residencial Flamboyant, 78.580-000, Alta Floresta, MT, Brasil.

${ }^{2}$ Universidade do Estado de Mato Grosso, Faculdade de Ciências Biológicas e Agrárias, Lab. Anatomia Vegetal, Campus de Alta Floresta, Residencial Flamboyant, 78.580-000, Alta Floresta, MT, Brasil.

${ }^{3}$ ORCID: <https://orcid.org/0000-0002-2086-4514>

${ }^{4}$ Autor para correspondência: julianadardengo@outlook.com
} 


\section{Introdução}

O gênero Hymenaea apresenta 14 espécies, sendo que 13 se encontram distribuídas pela América Central, América do Sul, oeste das Índias e uma espécie tem ocorrência no leste da África (Lima et al. 2009). No Brasil, a Hymenaea courbaril possui uma distribuição vasta, ocorrendo desde a floresta amazônica até a floresta estacional semidecidual no sudeste do país, com diversas variedades, sendo as mais comuns, $H$. courbaril var. courbaril., $H$. courbaril var. stilbocarpa, $H$. courbaril var. subsessilis, $H$. courbaril var. villosa (Filardi et al. 2018).

Os representantes de Hymenaea são popularmente conhecidos como jatobá, burandã, farinheira, jataí, jutaí, jataíba, jataiba-peba, jataíbauva, jataúba, juteí, jataí-amarelo, jataí-vermelho, jatal, jati, jassaí, jatobá de anta, jatobá de porco, jatabá trapuca, jetaí, jetaíba, jupiti, jutaí-açu, árvore-copal-do-Brasil, abotii-timbaí e jataici (Lorenzi \& Matos 2008). Hymenaea courbaril é geralmente uma árvore de grande porte, com folhas compostas por dois folíolos, inflorescência em panículas terminais e frutos em forma de vagens indeiscentes, apresentando de 6 a 8 sementes, envoltas por uma farinha comestível de grande valor nutritivo, consumida pelo homem como alimento e por animais, principalmente roedores (Gorchov et al. 2004).

No setor florestal, o jatobá é bastante utilizado pela indústria moveleira e de construção civil e naval (Costa et al. 2011), o que nos remete à importância de planos de manejo e conservação da espécie, já que a exploração da madeira ameaça seu uso medicinal, área em que a espécie apresenta significativa importância, uma vez que suas folhas e casca possuem compostos terpênicos e fenólicos que agem como anti-microbianos, anti-fúngicos, anti-bacterianos, moluscicidas, o que valida sua longa história de uso contra vários males (Lorenzi $\&$ Matos 2008). De acordo com Pinto \& Maduro (2003), o jatobá está entre os produtos de origem vegetal mais procurado para fins medicinais, sendo a casca e a resina indicadas como antianêmicos, para tratamento de próstata e inflamações. Outros trabalhos também relatam o uso medicinal do jatobá, como o trabalho de Amorozo (2002), no município de Santo Antônio do Leverger, Mato Grosso e Alcântara et al. (2005) município de Itaberaba, Bahia.

Contudo, ainda não se sabe exatamente onde estão localizados histologicamente os metabólitos secundários responsáveis pelas características medicinais da espécie, informação pertinente no auxílio na indicação da melhor parte do vegetal a ser utilizada em terapias, bem como, uma estratégia de redução de gasto e tempo na elaboração de futuros medicamentos, uma vez que a indústria farmacêutica tem na localização de metabólitos nos tecidos ou determinadas células vegetais uma ferramenta fundamental (Silva et al. 2010).

Assim, este trabalho teve como objetivo além de caracterizar a morfoanatomia, a histoquímica e fitoquímica dos órgãos vegetativos de $H$. courbaril, também histolocalizar as estruturas secretoras ou células secretoras que armazenam metabólicos secundários, cujas atribuições conferem potencial medicinal e verificar seu papel no desenvolvimento e sobrevivência da espécie.

\section{Material e Métodos}

Área de Estudo

O município de Alta Floresta encontra-se distante da capital Cuiabá $830 \mathrm{~km}$, e a vegetação é constituída pelas Florestas Ombrófilas Abertas e Densa, Florestas Estacionais e Formações Secundáriasdo Bioma Amazônico (IBGE 2015). Apresenta um clima equatorial continental úmido com estação seca definida da depressão sulamazônica, com temperatura média anual entre $24,3{ }^{\circ} \mathrm{C}$ e $24,8{ }^{\circ} \mathrm{C}$. O volume de precipitação pluviométrica é elevado ficando entre 2000 e $2300 \mathrm{~mm}$ (Seplan 2006). O relevo é formado pelo Planalto Apiacás-Sucurundi e a Depressão Interplanáltica Amazônia Meridional (Ross 2007).

A coleta do material vegetal foi realizada em indivíduos nativos de Hymenaea courbaril em uma propriedade particular no município de Alta Floresta, MT em 2015. Os indivíduos estão em uma área de conservação de vegetação nativa próximo a uma nascente de água da propriedade. A planta possui $2,2 \mathrm{~m}$ de circunferência a altura do peito e altura de 14 metros de altura.

\section{Morfoanatomia}

Amostras de caule e folíolos de Hymenaea courbaril foram levadas ao HERBAM (Herbário da Amazônia Meridional - UNEMAT), onde passou pelo processo de herborização utilizandose técnicas usuais (Fidalgo \& Bononi 1989). Posteriormente foi identificado e está em processo de deposição no HERBAM sobre o número de registro 11694. Foram utilizadas bibliografias especializadas para a diagnose do material realizado no HERBAM (Barroso et al. 1999; 
Radford et al. 1974). Parte do material biológico caule e folíolos foi analisada no Laboratório de Biologia Vegetal, da Universidade do Estado de Mato Grosso, Campus II, de Alta Floresta/MT, as amostras foram fixadas em FAA (formaldeído, ácido acético e etanol a 50\%; 1: 1: $18 \mathrm{vol} / \mathrm{vol}$ ). e foi estocado em etanol 70\% (Johansen 1940).

Para a análise anatômica foi escolhida a região mediana dos folíolos que compõem a folha da planta e a porção mediana do caule jovem, onde realizou-se secções transversais e longitudinais à mão livre, com o auxílio de lâminas de barbear. Os cortes foram corados com azul de Astra e fucsina básica (Roeser 1962) e montadas em lâminas histológicas semipermanentes com gelatina glicerinada (Kaiser 1880).

Para análise da epiderme foliar foram feitas secções paradérmicas na superfície adaxial e abaxial, sendo ainda dissociadas pelo método de Jeffrey (Kraus \& Arduim 1997) modificado. Para isso, foram armazenadas porções foliares nas dimensões de $1 \mathrm{~cm}^{2}$ em microtubos com peróxido de hidrogênio (volume 30) e ácido acético glacial na proporção de $1: 1$ e mantidas em estufa a $60^{\circ} \mathrm{C}$ por 48 horas. As lâminas foram analisadas em fotomicroscópio Leica ICC50 acoplado a um computador e analisadas no software LAS EZ versão 1.7.0. Após caracterização anatômica dos indivíduos estudados foram elaboradas pranchas confeccionadas com as fotomicrografias.

\section{Testes histoquímicos}

Secções histológicas dos materiais vegetais frescos (caule e folíolos) foram obtidas a mão livre com auxílio de lâminas de alumínio. Os cortes foram submetidos a testes histoquímicos com Lugol para a identificação de amido (Johansen 1940), Sudan IV (Pearse 1980) para compostos lipídicos totais, reagente de NADI (David \& Carde 1964) para óleos essenciais, Vanilina clorídrica (Mace \& Howell 1974) para taninos, Cloreto férrico III (Johansen 1940) para compostos fenólicos e reagente de Dragendorff (Svendsen \& Verpoorte 1983), para alcalóides. O teste com Ácido tânico (Pizzolato \& Lillie 1973) foram para a identificação de mucilagem, Tricloreto de antimónio (Hardman \& Sofowora 1972) para detecção de esteróides, 2-4-Dinitrofenilhidrazina (Ganter \& Jollés 1970) para terpenóides e Ácido Sulfúrico (Geissman \& Griffin 1971) para identificação de lactonas sesquiterpénicas.

Testes controle foram realizados simultaneamente, de acordo com as recomendações dos respectivos autores para cada teste citado e para auxiliar na aplicação dos testes utilizouse como bibliografias de base Ventrella et al. (2013) e Ascensão (2004). Os resultados foram documentados por meio de fotomicroscópio Leica ICC50 acoplado a um computador e analisadas no software LAS EZ versão 1.7.0., sendo posteriormente confeccionadas pranchas a partir das fotomicrografias de aspectos gerais da espécie e dos testes que resultaram positivamente.

\section{Prospecção fitoquímica}

Para realização do estudo fitoquímico, o material vegetal (caule e folíolos) foi conduzido ao Laboratório de Biologia Vegetal da Universidade do Estado de Mato Grosso/ $\mathrm{AF}$, onde foi lavado com água destilada e posteriormente devidamente identificado, pesado a massa fresca, obtendo $150 \mathrm{~g}$ de cada órgão (caule e folíolos). Na sequência o material foi submetido à secagem em estufa de circulação de ar em uma temperatura de $40^{\circ} \mathrm{C}$, por 72 horas.

Posteriormente, o material foi novamente pesado para cálculo do rendimento de massa seca, sendo utilizado $30 \mathrm{~g}$ de cada órgão (caule e folíolo). Após este procedimento o material foi pulverizado em moinho tipo Willey e obtido o rendimento do material vegetal pulverizado $(20 \mathrm{~g}$ de cada órgão). O material vegetal pulverizado foi acondicionado em sacos de papel e conservado em geladeira $\left(6^{\circ} \mathrm{C}\right.$ a $\left.10{ }^{\circ} \mathrm{C}\right)$.

Os testes fitoquímicos foram realizados no laboratório de Biotecnologia e Recursos Genéticos da Universidade Estadual de Montes Claros/MG. A metodologia adotada foi de acordo com Mouco et al. (2003), Lima et al. (2009), Rodrigues et al. (2009) e Silva et al. (2010) com modificações para antraquinonicos (foi pesado $1 \mathrm{~g}$ da droga adicionando-se $20 \mathrm{ml}$ de etanol $75 \%$; então, aqueceu-se por dois minutos em banho-maria e foi filtrado; ao que resultou da filtragem adicionouse $10 \mathrm{ml}$ de ácido clorídrico $10 \%$, a amostra foi levada ao funil de separação e adicionado $5 \mathrm{ml}$ de clorofórmio e extraída a fase orgânica, que foi levada ao tubo de ensaio e adicionou-se uma a duas gotas de hidróxido de sódio), cardiotônicos (foram pesados $2 \mathrm{~g}$ da droga, adicionou-se $20 \mathrm{ml}$ de etanol $70 \%$, aqueceu-se por dois minutos em banho maria e filtrado; ao resultante da filtragem adicionou-se $20 \mathrm{ml}$ água destilada, sendo levado ao funil de separação, adicionado $16 \mathrm{ml}$ de clorofórmio e extraída a fase orgânica) e alcalóides (a reação foi efetuada em tubo de ensaio). 
Para as detecções foram realizadas as reações: a) taninos: cloreto férrico $2 \%$, solução aquosa de alcalóides, acetato neutro de chumbo $10 \%$, solução de acetato de cobre $5 \%$, acetato de chumbo $10 \%$ e ácido acético glacial $10 \%$ e gelatina $2 \%$; b) alcalóides: os reagentes de Borchardt, de Bertrand, de Mayer e de Dragendorff, modificado, sendo as reações realizadas em tubo de ensaio; c) flavonoides: as reações de Shinoda, cloreto de alumínio $5 \%$, cloreto férrico e hidróxido de sódio; d) saponinas: o teste de espuma 15 minutos. e) antraquinonas: reações de Borntrãeger e hidróxido de sódio. Foi pesado $1 \mathrm{~g}$ do material estudado, adicionando-se $20 \mathrm{~mL}$ de etanol $75 \%$; então, aqueceu-se por dois minutos em banhomaria e foi filtrado. Ao resultante da filtragem adicionou-se $10 \mathrm{~mL}$ de ácido clorídrico $10 \%$ e levado ao funil de separação, sendo adicionado 5 $\mathrm{mL}$ de clorofórmio e extraída a fase orgânica, que foi levada ao tubo de ensaio e adicionada de uma a duas gotas de hidróxido de sódio; f) glicosídeos cardiotônicos: reações de Liebermann-Burchard e de Keller-Killiani, modificado, onde foram pesados $2 \mathrm{~g}$ do produto adicionando $20 \mathrm{~mL}$ de etanol $70 \%$, sendo aquecido por dois minutos em banho-maria e posteriormente filtrado. Ao resultante da filtragem adicionou-se $20 \mathrm{~mL}$ água destilada, sendo levado ao funil de separação, adicionado $16 \mathrm{~mL}$ de clorofórmio e extraída a fase orgânica; g) esteroides e terpenoides: reação de Liebermann-Burchard.

\section{Resultados}

\section{Anatomia do caule}

O córtex é composto por células parenquimáticas de preenchimento, com células arredondadas, de tamanhos variados, com pequenos espaços intercelulares e com presença de possivelmente sílica (Fig.1a-d).

A epiderme caulinar é uniestratificada, justaposta, com células de formato arredondado (Fig. 1e). Os feixes vasculares são colaterais, com região cambial definida, em formato de arco e rodeados de fibras vasculares (Fig.1e). Ao centro observa-se presença de medula parenquimática com presença de cavidade secretora (Fig 1e).

Tricomas tectores recobrem toda a superfície epidérmica do caule (Fig.1e). Abaixo da epiderme, nota-se o estabelecimento do felogênio em vários estágios de desenvolvimento, conferindo neste caso o, crescimento secundário ao caule (Fig. 1e).
É também no córtex que estão concentrados as cavidades secretoras, compostas por um epitélio celular com 18 a 20 células (Fig. 1e).

\section{Anatomia do folíolo}

Os folíolos de Hymenaea courbaril são hipoestomáticos, apresentando estômatos do tipo paracítico. Em vista frontal as células epidérmicas são de paredes sinuosas e espessas em ambas as faces foliares (Fig. 2a,b). Os feixes vasculares são colaterais, circundado por fibras (Fig. 2c). Na região da nervura principal os feixes de fibras são maiores, apresentando grande quantidade de elementos de condução (Fig. 2d).

A epiderme é uniestratificada de formato irregular com as paredes e cutículas espessadas (Fig. 2d). O mesofilo foliar é dorsiventral, sendo composto de 2-4 camadas de parênquima paliçádico e 1-2 de parênquima lacunoso (Fig. 2d). Foi constatada a presença de cavidades secretores do tipo lisígena esparsos no mesofilo (Fig. 2e). $\mathrm{Na}$ região da nervura principal abaixo da face epidérmica abaxial, observa-se a presença de provavelmente braquiesclereídes (Fig. 2f).

Em secção transversal, verifica-se que os estômatos estão situados no mesmo nível das demais células epidérmicas e com câmara subestomática desenvolvida (Fig. 2g).

\section{Histoquímica}

$\mathrm{O}$ teste histoquímico com Vanilina revelou a presença de taninos nas células parenquimáticas próximas às cavidades secretoras no caule e nos folíolos (Fig. 3a,b). O reagente de NADI detectou óleos essenciais nos canais de secreção em ambos os órgãos (Fig. 3c,d).

O Sudan IV foi positivo para o teste de lipídeos no interior das cavidades secretoras do caule e nos folíolos apresentou-se nas células do epitélio da cavidade (Fig. 3e,f).

$\mathrm{O}$ teste de Lieberman-Burchard constatou a presença de esteróides apenas nos folíolos (Tab. 1). O teste com Ácido sulfúrico revelou a presença de Lactonas sesquiterpénicas nos folíolos, sendo negativo para o caule (Tab. 1). A partir da reação com 2,4 - Dinitrofenilhidrazina detectou-se terpenóides nas cavidades secretoras em ambos os órgãos analisados (Fig. 3i,j).

O Cloreto de ferro III $10 \%$ detectou a presença de mucilagens em ambos os órgãos (Fig. 3 k,l).Os testes Lugol, Dragendorff, Ácido tânico e Cloreto de ferro III 3\% para detecção de amido, 


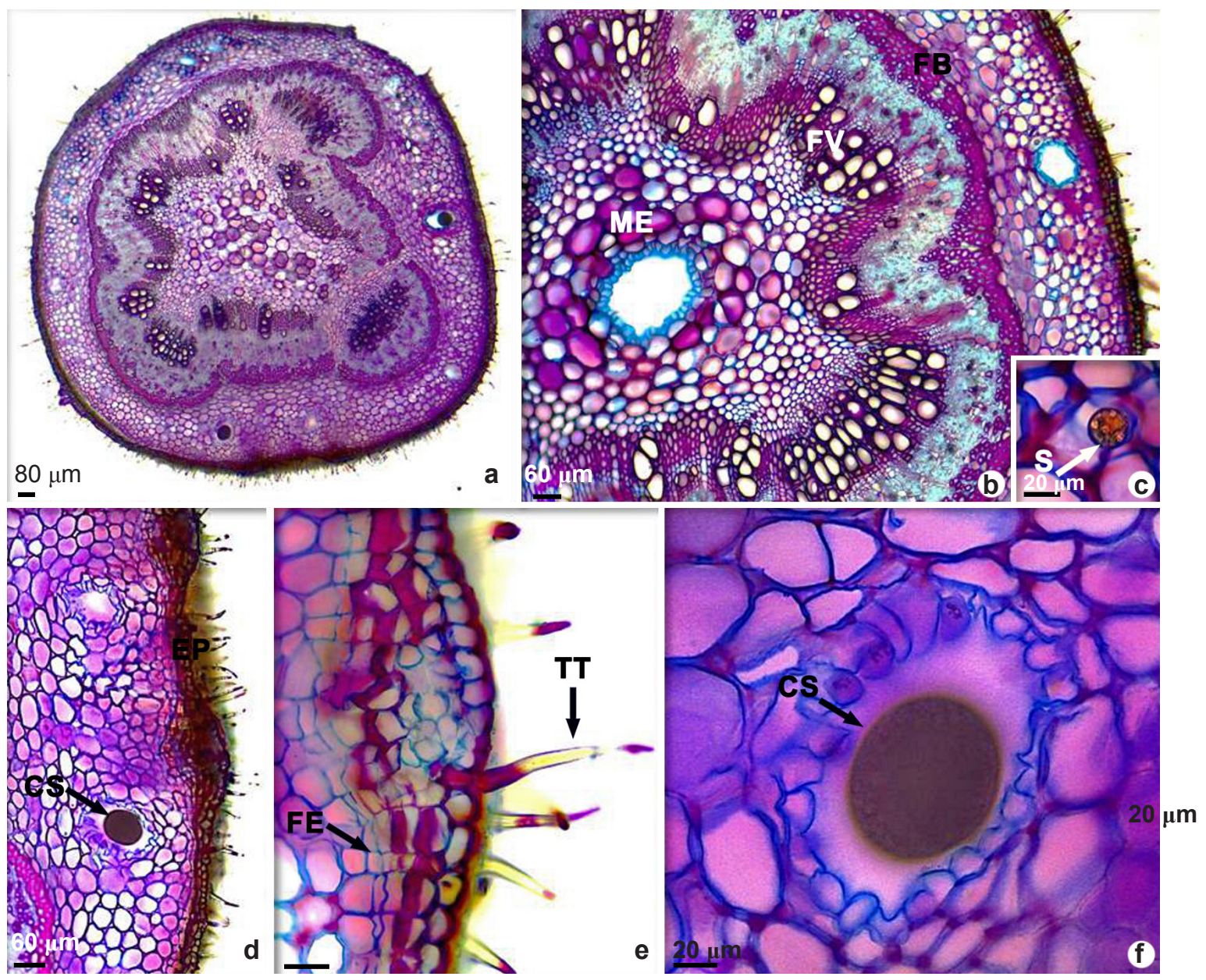

Figura 1 - a-f. anatomia do caule de Hymenaeacourbarilem secções transversais - a. aspecto geral do caule; b. epiderme, córtex, feixe vascular e medula; c. detalhe da sílica no parênquima; d. aspecto do córtex; e. detalhe da epiderme e tricomas; f. detalhe do canal de secreção. ME: Medula; FV: Feixe Vascular; FB: Feixe de Fibra; S: Sílica; CS: Cavidade secretora; EP: Epiderme; FE: Felogênio; TT: TricomaTector.

Figure 1 - a-f. anatomy of the stem of Hymenaeacourbaril in cross sections - a. general aspect of the stem; b. epidermis, cortex, vascular bundle and medulla; c. detail of the silica in the parenchyma; $d$. aspect of the cortex; e. detail of the epidermis and trichomes; f. detail of secretion channel. ME: Bone marrow; FV: Vascular Bundle; FB: Fiber beam; S: Silica; CS: Secretory cavity; EP: Epidermis; FE: Felogênio; TT: TricomaTector.

alcaloides e compostos fenólicos, foram negativos em ambos os órgãos estudados.

\section{Fitoquímica}

As análises fitoquímicas foram positivas para a identificação de taninos no caule e folíolos de $H$. courbaril (Tab. 1) de acordo com as reações, cloreto férrico $2 \%$, Acetato de cobre $5 \%$, e acetato neutro de chumbo $10 \%$, exceto ácido acético glacial $10 \%$.

$\mathrm{Na}$ identificação de flavonóides, o teste magnésio e ácido clorídrico foi negativo no caule e positivo no folíolo. Cloreto férrico $2 \%$, Cloreto de alumínio 5\% e Hidróxido de sódio 5\% reagiu positivamente para os órgãos em estudo.
Os testes com Reativo de Bortranger, Hidróxido de sódio $0,5 \%$ para Glicosídeos antraquinônicos e o teste de espuma para deteç̧ão de saponinas foram positivos para a espécie no caule e nos folíolos. Os Glicosídeos cardiotônicos não foram detectados no caule e nos folíolos com a reação de LiebermanBurchard, já para reação de Keller-Kiliani, o resultado foi positivo em ambos os órgãos estudados.

Terpenos e esteróides estão presentes apenas nas folhas detectados pelo teste de LiebermanBurchard. Nos testes de Mayer, Bouchardat, Bertrand e Dragendorff para detectar alcaloides apresentaram reações negativas tanto no caule quanto nos folíolos. 

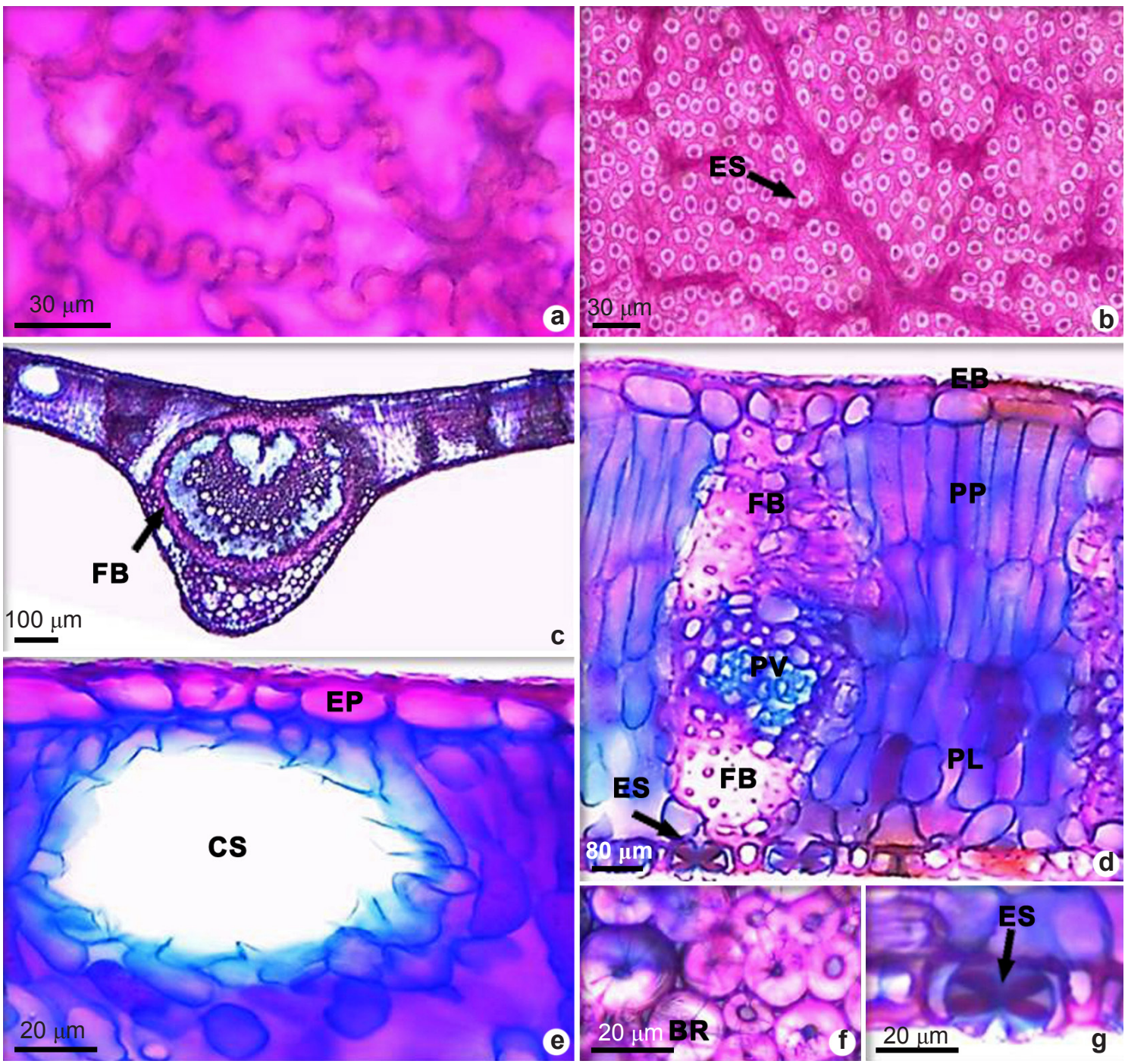

Figura 2 - a-g. Anatomia da folha de Hymenaeacourbarilem secções transversais e paradérmicas - a. face adaxial; b. face abaxial com a disposição geral dos estômatos; c. aspecto geral da nervura principal; d. aspecto do mesofilo foliar; e. canais de secreção; f. detalhe dos braquiesclereídeos; g. estômato em secção transversal. FV: Feixe Vascular; FB: Feixe de Fibra; CS: Cavidade secretora; EP: Epiderme; PP: Parênquima Paliçádico; PL: Parênquima Lacunoso; BR: Braquiesclereídeo; ES: Estômato.

Figura 2 - a-g. Anatomy of the leaf of Hymenaeacourbarilin transverse and paradermic sections - a. adaxial face; b. abaxial face with the general arrangement of the stomata; c. general aspect of the main vein; d. aspect of leaf mesophyll; e. secretion channels; f. detail of the brachyceclereids; g. stomata in cross-section. FV: Vascular Bundle; FB: Fiber beam; CS: Secretory cavity; EP: Epidermis; PP: Paliçádico parenchyma; PL: Lacunar parenchyma; BR: Brachysclereide; ES: Stomata

\section{Discussão}

A partir dos órgãos vegetativos analisados verificou-se que as estruturas de secreção de Hymenaea courbaril são cavidades secretoras, distribuídas no caule e no folíolo. Cutter (1986) relata que células de secreção aparecem em diferentes partes da planta e tipos particulares de estruturas de secreção são, às vezes, características de certas famílias. Para a família Leguminosae a presença de canais de secreção que apresentam compostos secundários é considerada um caractere de cunho quimiotaxonômico (Esau 1976; Bessa et al. 2013). A existência destes compostos, também é fundamental como mecanismo de defesa e sobrevivência de plantas pertencentes a esta família (Oliveira et al. 2011). 

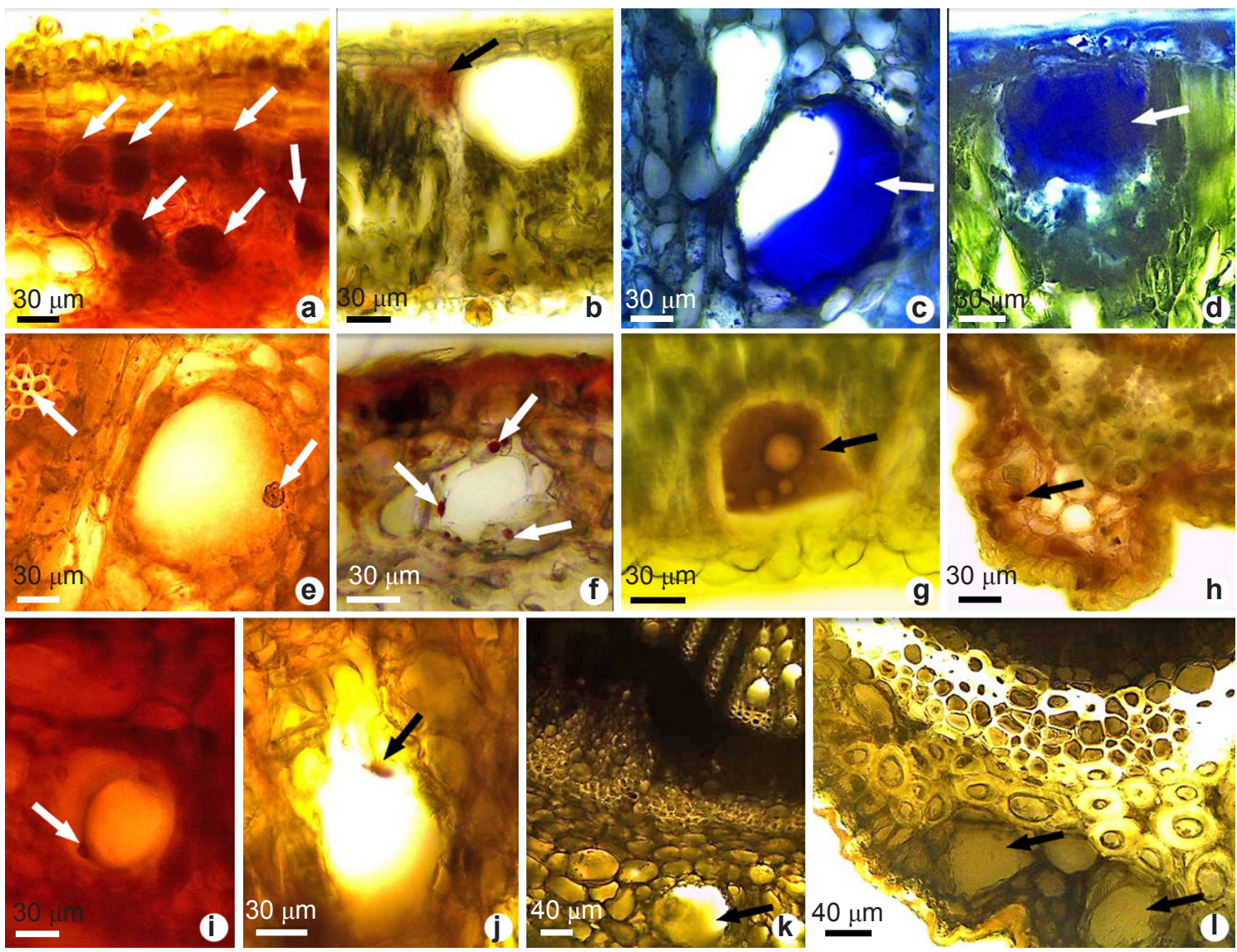

Figura 3 -a-1. secções transversais do caule e folha de Hymenaea courbaril, evidenciando os testes histoquímicos positivos indicados pelas setas - a. vanilina no caule; b. vanilina na folha; $c$. reagente de NADI no caule; d. reagente de NADI na folha; e. sudan IV no caule; f. sudan IV na folha; g. tricloreto de antimônio na folha; h. ácido sulfúrico na folha; i. 2,4-dinitrofenilhidrazina no caule; j. 2,4-dinitrofenilhidrazina na folha; $\mathrm{k}$. cloreto de ferro III 10\% no caule; 1 . cloreto de ferro III $10 \%$ na folha.

Figura 3 -a-l. cross sections of the stem and leaf of Hymenaea courbaril, showing the positive histochemical tests indicated by the arrows - a. vanillin on the stem; b. vanillin on the leaf; c. NADI reagent on the stem; d. NADI reagent on the leaf; e. sudan IV on the stem; f. sudan IV on the leaf; g. antimony trichloride in the leaf; h. sulfuric acid in the leaf; i. 2,4-dinitrophenylhydrazine on the stem; j. 2,4-dinitrophenylhydrazine in the leaf; $\mathrm{k}$. iron chloride III $10 \%$ on the stem; 1 . iron chloride III $10 \%$ in the leaf.

A presença de compostos como flavonóides confere atividade antimicrobiana a Hymenaea courbaril (Gonçalves et al. 2005). Bessa et al. (2013) ressaltam que a presença dos flavonóides combinado com taninos indica atividade antiinflamatória (Bessa et al. 2013). Os taninos, geralmente se localizam em órgãos específicos da planta como nas folhas, frutos ou caules (Roberts et al. 1997). Uma das principais características da presença de taninos nesta espécie é seu efeito adstringente, sendo esta atividade biológica fundamental no tratamento de doenças do trato digestivo conforme descrito por Bessa et al. (2013) para outras espécies. Taninos quando associados a proteínas promovem a defesa das plantas contra ataques de insetos, fungos e bactérias (Valentim 2006).

Os óleos essenciais podem ser extraídos de frutos, folhas e resina (Panizza 1997; Pinto et al. 2000). Folhas, casca, resina e frutos de jatobá possuem compostos que tem ação antimicrobiana, antifúngica, antioxidante, anti-inflamatória, larvicida e moluscocida (Gonçalves et al. 2011; Cecílio et al. 2012). Quanto a atividade larvicida de $H$. courbaril, Aguiar et al. (2010) ao testarem em diferentes concentrações de óleos essenciais extraídos dos frutos verdes e maduros, constataram forte atividade biológica no controle de larvas do mosquito Aedes aegypti, corroborando os testes histoquímicos realizados com ambos os órgãos 
Tabela 1 - Caracterização fitoquímica do caule e folíolo de Hymenaeacourbaril.

Table 1 - Phytochemical characterization of stem and leaflet of Hymenaeacourbaril.

\begin{tabular}{|c|c|c|c|}
\hline Metabólito secundário & Reativo/Teste & Caule & Folíolos \\
\hline \multirow{4}{*}{ Taninos } & Cloreto férrico $2 \%$ & +++ & +++ \\
\hline & Acetato neutro de chumbo $10 \%$ & ++ & +++ \\
\hline & Acetato de cobre $5 \%$ & ++ & ++ \\
\hline & Ácido acético glacial 10\% & - & ++ \\
\hline \multirow{4}{*}{ Flavonóides } & Magnésio + ácido clorídrico & +++ & - \\
\hline & Cloreto férrico $2 \%$ & +++ & ++ \\
\hline & Cloreto de alumínio 5\% & + & + \\
\hline & Hidróxido de sódio 5\% & ++ & + \\
\hline \multirow{2}{*}{ Glicosídeos antraquinônicos } & Reativo de Bortranger & $+(\mathrm{a})$ & $+(\mathrm{v})$ \\
\hline & Hidróxido de sódio $0,5 \%$ & $+(\mathrm{a})$ & $++(\mathrm{a})$ \\
\hline Saponinas & Teste da espuma & + & +++ \\
\hline \multirow{2}{*}{ Glicosídeos Cardiotônicos } & Lieberman-Burchard & - & - \\
\hline & Keller-Kiliani & +++ & + \\
\hline Terpenóides/Esteróides & Lieberman-Burchard & - & ++ \\
\hline \multirow{4}{*}{ Alcalóides } & Mayer & - & - \\
\hline & Bouchardat & - & - \\
\hline & Bertrand & - & - \\
\hline & Dragendorff & - & - \\
\hline
\end{tabular}

a- coloração amarela: antraquinona reduzida; v-coloração vermelha: antraquinona oxidada;(+++)Forte;(++) Moderado; (+)Fraco; (-)Negativo.

estudados neste trabalho. Tornando-se uma opção para o controle deste mosquito que transmite dengue, chikungunya e zika.

Já os lipídios, constituintes da membrana celular, podem auxiliar na prevenção de perda de água excessiva, bem como na resistência a doenças (Menezes et al. 2003; Taiz \& Zeiger 2004). Vale ressaltar que o resultado de presença dos lipídios detectados em $H$. courbaril corroboram o trabalho de Silva et al. (2012) que estudou anatomia dos órgãos vegetativos de Hymenaea martiana Hayne, espécie de uso medicinal em CaetitéBA, demonstrando assim que este metabólito é compartilhado por outras espécies do gênero. Entre os trabalhos que apontam para a importância de estruturas secretoras de espécies vegetais, estão o de Meira et al. (2014) com Chamecrista dentata
(Vogel) H.S. Irwin \& Barneby, em que descrevem o processo de secreção das glândulas da parte aérea da espécie e sua importância no processo adaptativo da mesma. Coutinho et al. (2015) também com o gênero Chamecrista (L.) Moench, analisaram 55 espécies e concluíram que os componentes identificados na secreção dos coléteres sugerem que essas estruturas estão envolvidas na proteção de flores e folhas em desenvolvimento, sendo características importantes na elucidação da filogenia e taxonomia do gênero. Rodrigues et al. (2011) em seu estudo com sistema secretor de oleorresina de plântulas de Copaifera langsdorffii Desf. relataram a presença de compostos lipídicos e hidrofílicos em canais e cavidades e de resina apenas nos canais, os autores também ressaltam que a presença dessas substâncias tem sido associada 
com defesas da planta contra a desidratação, assim como contra a herbivoria e patógenos tanto no estágio de mudas como nos demais.

A presença de esteróides e terpenos nos órgãos estudados confere a esta espécie ação antiespasmódica, anti-inflamatória, antiparasitária e antihepatotóxica (Nogueira et al. 2001; Di Stasi \& Hiruma-Lima 2002; Chagas-de-Paula 2010). Já a presença de lactonas sesquiterpénicas que é relatada em $H$. courbaril é apontada como sendo supressora de apetite em larvas e insetos (Tincusi et al. 1998). Tais produtos depois de ingeridos, promovem a redução do crescimento, e aumentam o número de dias da pupa, reduzindo assim o peso da pupa ou a sobrevivência de besouros (Picman 1986; Harborne 1993).

Estudos fitoquímicos de perfil medicinal realizados com as cascas dos frutos de $H$. courbaril apontaram a presença de sesquiterpenos, assim como detectados no caule e folíolos neste estudo, novamente confirmando seu potencial medicamentoso no tratamento de doenças de origem cancerígena, pasmódica, inflamatória, microbiana e fúngica (Vale 2012).

Ao traçar o perfil fitoquímico de $H$. courbaril, Bezerra (2013) considerou a presença de glicosídeos antraquinônicos para seu caule. As análises realizadas neste estudo além de corroborar as observações de Bezerra (2013), também apontam sua presença nos folíolos desta espécie. Além disso, notou-se também a presença de glicosídeos cardiotônicos nos folíolos, estas substâncias possuem potencial de uso no tratamento de doenças cardíacas (Vickery \& Vickery 1981) e atividade medicinal sob o tecido do músculo cardíaco (Foglio et al. 2006).

Plantas que possuem metabólitos secundários como flavonóides, terpenos, saponinas e óleos essenciais têm efeito hepatoprotetor, tais características corroboram o que é relatado pela medicina popular, o que justifica sua utilização por ser hepatoprotetora (Borella et al. 2006). Compostos secundários desempenham funções de proteção ou de sinalização bioquímica (Bernards 2010). Além de contribuir como medicamento, segundo Kaufman et al. (1998), tais substâncias encontradas em $H$. courbaril desempenham um importante papel ecológico como estratégia reprodutiva e de defesa contra a herbivoria.

\section{Conclusão}

A presença de cavidades secretoras no folíolo e caule de Hymenaea courbaril, bem como dos metabólitos secundários identificados neste estudo elucidam a importância da espécie para fins medicinais e também seu papel ecológico no que tange mecanismos de defesa contra a herbivoria e a desidratação. Trabalhos nas áreas de etnobotânica e ecologia podem ser direcionados com base nos resultados obtidos neste trabalho, no sentido de evidenciar a interação do jatobá com outras espécies, com o ambiente e com comunidades tradicionais.

\section{Referências}

Aguiar JC, Santiago GMP, Lavor PL, Veras HN, Ferreira YS, Lima MA, Arriaga AM, Lemos TL, Lima JQ, Jesus HC, Alves PB \& Braz-Filho R (2010) Chemical constituents and larvicidal activity of Hymenaea courbaril fruit peel. Natural Product Communication 5: 1977-1980.

Alcântara JPJ, Osuna JTA, Queiroz SROQ \& Rias AP (2005) Levantamento etnobotânico eetnofarmacológico de plantas medicinais do município de Itaberaba - BA, para cultivo e preservação. Sitientibus, série Ciências Biológicas 5: $39-44$.

Amorozo MC de M (2002) Uso e diversidade de plantas medicinais em Santo Antonio do Leverger, MT. Acta Botanica Brasílica16: 189-203.

Ascensão L (2004) Métodos histoquimicos em vegetais. UFV, Viçosa. 198p.

Barroso GM, Morim MP, Peixoto AL \& Ichaso CLF (1999) Frutos e sementes: morfologia aplicada à sistemática de dicotiledôneas. Editora UFV, Viçosa. $228 \mathrm{p}$.

Bernards MA(2010) Plant natural products: a primer The present review is one in the special series of reviews on animal-plant interactions. Canadian Journal of Zoology 88: 601-614.

Bessa NGF, Borges JCM, Beserra FP, Carvalho RHA, Pereira MAB, Fagundes R \& Alves A (2013) Preliminary phytochemical screening of native Cerrado plants of medicinal popular use by the rural community of the Vale Verde settlementTocantins. Revista Brasileira de Plantas Medicinais 15: 692-707.

Bezerra GP (2013) Estudo farmacoquímico bioguiado pela atividade miorrelaxante do extrato etanólico das cascas do caule de Hymenaea courbarill. (jatobá). Dissertação de Mestrado. Universidade Federal do Ceará, Fortaleza. 129p.

Borella JC, Duarte DP, Novaretti AAG, Menezes JRA, França SC, Rufato CB, Santos PAS, Veneziani RCS \& Lopes NP (2006) Variabilidade sazonal do teor de saponinas de Baccharistrimera (Less.) DC (Carqueja) e isolamento de flavona. Revista Brasileira de Farmacognosia 16: 557-561. 
Cecílio AB, Faria DB, Carvalho Oliveira P, Caldas S, Oliveira DA, Sobral MEG \& Almeida VL (2012) Screening of Brazilian medicinal plants for antiviral activity against rotavirus. Journal of Ethnopharmacology 141: 975-981.

Chagas-de Paula DA (2010) Atividade anti-inflamatória e fitoquímica do chá e de diferentes extratos de Tithoni adiversifolia(Asteraceae). Dissertação de Mestrado. Universidade São Paulo, Ribeirão Preto. 116p.

Costa WS, Souza AL \& Souza PB (2011) Ecologia, manejo, silvicultura e tecnologia de espécies nativas da Mata Atlântica. UFV, Viçosa. 18p.

Coutinho IAC, Francino DMT \& Meira RMSA (2015) New records of colleters in Chamaecrista (Leguminosae, Caesalpinioideaes.1.): structural diversity, secretion, functional role, and taxonomic importance. International Journal of Plant Sciences 176: 72-85.

Cutter EG (1986) Anatomia vegetal. Parte I: células e tecidos. $2^{\mathrm{a}}$ ed. Rocca, São Paulo. 123p.

David R. \& Cardè RJP (1964) Coloration différentielle des inclusions lipidiques et terpéniques des pseudophylles du Pin maritime au moyen du réactifnadi. Paris: ComptesRendus de l'Académie des Sciences. Serie Iii-Sciencesdelavie-life Sciences 258: 338-1340.

Di Stasi LC \&Hiruma-Lima CA (2002) Plantas medicinais na Amazônia e na Mata Atlântica. $2^{\mathrm{a}}$ ed. UNESP, São Paulo. 126p.

Esau K (1976) Anatomia das plantas com sementes. Edgard Blucher, São Paulo. 210p.

Fidalgo O \&Bononi VLR (1989) Técnicas de coleta, preservação e herborização do material botânico. Instituto de Botânica, São Paulo. 61p.

Filardi FLR et al. (2018) Brazilian Flora 2020: Innovation and collaboration to meet Target 1 of the Global Strategy for Plant Conservation (GSPC). Rodriguésia 69: 1513-1527.

Foglio MA, Queiroga CL, Sousa IDO \& Rodrigues RAF (2006) Plantas medicinais como fonte de recursos terapêuticos: Um modelo multidiciplinar. Multiciências 7: 1-8.

Ganter P \&Jollès G (1970) Histologienormale et pathologique. Vols. 1 e 2. Gauthier, Paris. 55p.

Geissman TA \& Griffin TS (1971) Sesquiterpen lactones: acid-catalized color reactions as an in structure determination. Phytochemistry 10: 2475-2485.

Gonçalves AL, Alves Filho A \& Menezes H (2011) Efeitos antimicrobianos de algumas plantas medicinais brasileiras em disordens intentinais. Saúde e Pesquisa 4: 103-113.

Gonçalves AL, Alves Filho A \& Menezes H (2005) Estudo comparativo da atividade antimicrobiana de extratos de algumas árvores nativas. Instituto Biológico 72: 353-358.

Gorchov DL, Palmeirim JM, Jaramillo M \& Ascorra CF (2004) Dispersal of seeds of Hymenaea courbaril (Fabaceae) in a logged rain forest in the Peruvian Amazonian. Acta Amazônica 34: 251-259.

Harborne JB (1993) Advances in chemical ecology. Natural Product Reports 10: 327-348.

Hardman RE \& Sofowora EA (1972) Antimony trichloride as test reagentes for steroids, especially diogenin and yamogenion, in plant tissues. StainTechnol 47: 205-208.

IBGE - Instituto Brasileiro de Geografia Estatística (2016) Disponível em <http://cidades.ibge.gov.br/ xtras/perfil.php?codmun $=510025>$. Acesso em 11 janeiro 2016.

Johansen DA (1940) Plant microtechnique. MacGrawHill Book Company, New York. 127p.

Kaiser E (1880) VerfahrenzurHerstellungeinertadellosen Glycerin-Gelatine. Botanisch Zentralb 1: 25-26.

Kaufman PB, Cseke LJ, Duke JA \& Brielmann HL (1998) Natural products from plants. CRC Press, London, New York. 632p.

Kraus JE \&Arduin M (1997) Manual básico de métodos em morfologia vegetal. Ed. Universidade Rural, Rio de Janeiro. 230p.

Lima JM, Silva CA, Roza MB, Santos JB, Oliveira TG, Silva MB (2009) Prospecção fitoquímica de Sonchus oleraceus e sua toxidade sobre o microcrustáceo Artemia salina. Planta Daninha 27: 7-11.

Lorenzi H \& Matos FJA (2008) Plantas medicinais no Brasil Nativas e exóticas. $2^{\mathrm{a}}$ ed. Instituto Plantarum, Nova odessa. 544p.

Mace ME \& Howel LCR (1974) Histochemistry and identification of condensed tannin precursor in root of cotton seedlings. Canadian Journal of Botany 52: 2423-2426.

Meira RMSA, Francino DMT \&Ascensão L (2014) Oleoresin Trichomes of Chamaecrista dentata (Leguminosae): structure, function, and secretory products. International Journal of Plant Sciences 175: 336-345.

Menezes NL, Silva DC \& Melodepinna GFA (2003) Folha. In: Appezzato-daGlória B \& CarmelloGuerreiro SM Anatomia Vegetal. Editora UFV, Viçosa. Pp. 303-311.

Mouco GB, Bernardinho MJ \& Cornélio ML (2003) Controle de qualidade de ervas medicinais. Biotecnologia Ciência e Desenvolvimento 31: 68-73.

Nogueira RT, Shepherd GJ, Laverde JRA, Marsaioll AJ \& Imamura PM (2001) Clerodane-type diterpenes from the seed pods of Hymenaea courbaril var. stilbocarpa. Phytochemistry 58: 1153-1157.

Oliveira MMM, Brugnera DF, Cardoso MG, Guimarães LGL \&Piccoli RH (2011) Rendimento, composição química e atividade antilisterial de óleos essenciais de espécies de Cymbopogon. Revista Brasileira de Plantas Medicinais 13: 8-16.

Panizza S (1997) Plantas que curam: (cheiro de mato). $15^{\mathrm{a}}$ ed. Ibrasa, São Paulo. 279p. 
Pearse A (1980) Histochemistry theorical and apllied. $4^{\mathrm{a}}$ ed. Longman, London. 246p.

Picman AK (1986) Biological activities of sesquiterpene lactones. Biochemical Systematicsand Ecology 14: 255-281.

Pinto A da C \& Maduro CB (2003) Produtos e subprodutos da medicina popular comercializados na cidade de Boa Vista, Roraima. Acta Amazônica 33: 281-290.

Pinto JEBP, Santiago EJA \& Lameira OA (2000) Compêndio de plantas medicinais. UFLA/FAEPE, Lavras. 184p.

Pizzolato TD \& Lillie RD (1973) Mayer's tannic acidferric chloride stain for mucins. The Journal of Histochemistry and Cytochemistry 21: 56-64.

Radford AE, Dickison WC, Massey JR \& Bell CR (1974) Vascular plant systematics. Harvard University, New York. 888p.

Roberts JE, Speedie MK \& Tyler VE (1997) Farmacognosia e farmacobiotecnologia. Premier, São Paulo. 93p.

Rodrigues RR, Lima RAF, Gandolfi S \& Nave AG (2009) On the restoration of high diversity forests: 30 years of experiences in the Brazilian Atlantic Forest. Biological Conservation 142:1242-1251.

Rodrigues TM, Teixeira SP \& Machado SR (2011) The oleoresin secretory system in seedlings and adult plants of copaíba (Copaifera langsdorffii Desf., Leguminosae-Caesalpinioideae). Flora 206:585594.

Roeser KR (1962) Die Nadel der Schwarzkiefer Massenprodukt und Kunstwerk der Natur. Mikrokosmos 61:33-36.

Ross JS (2007) O relevo no processo de produção do espaço. In: Moreno G, Santos GV, Dias HCT, Silva APS \& Macedo MNC. Análise hidrológica e socioambiental da bacia hidrográfica do córrego Romão dos Reis, Viçosa-MG. Revista Árvore 31: 931-940.
SEPLAN - Secretaria de Estado de Planejamento e Coordenação Geral (2006) Unidades climáticas do estado de Mato Grosso. In: Zoneamento Sócio Econômico Ecológico. CD-Rom do Atlas Climatológico de Mato Grosso. PRODEAGRO, Cuiabá. 387p.

Silva MS, Leite KRB \& Saba MD (2012) Anatomia dos órgãos vegetativos de HymenaeamartianaHayne (Caesalpinioideae-Fabaceae): espécie de uso medicinal em Caetité-BA. Revista Brasileira de plantas medicinais 14: 673-679.

Silva NLA, Miranda FAA \& Conceição GM (2010) Triagem fitoquímica de plantas de cerrado, da área de proteção ambiental municipal do Inhamum, Caxias, Maranhão. Scientia Plena 6: 1-17.

Svendsen BA \& Verpoorte R (1983) Cromatografia de alcalóides parte A: cromatografia em camada fina. Elsevier, Amsterdã/Oxford/Tóquio. 6: 1-19.

Taiz L \& Zeiger E (2004) Fisiologia vegetal. Artmed, Porto Alegre. 339p.

Tincusi BM, Jiménez IA, Ravelo AG \& Missico R (1998) New Sesquiterpenes from Crossopetalum tonduzii. Journal of natural products 61: 1520-1523.

Vale CR (2012) Avaliação da atividade tóxica, genotóxica e antigenotóxica de Hymenaea courbaril L. em camundongos e Drosophila melanogaster. Dissertação de Mestrado. Universidade Federal de Goiás, Goiânia. 126p.

Valentim APT (2006) Na atividade antimicrobiana, estudo fitoquímico e identificação de constituintes apolares do alburno de Hymenaea stigonocarpa Mart. ex Hayne (jatobá). Dissertação de Mestrado. Universidade Federal de Pernambuco, Recife. 125p.

Ventrella MC, Almeida AL, Ner LA \& Miranda Coelho VP (2013) Métodos histoquímicos aplicados a sementes. UFV, Viçosa.

Vickery ML \&Vickery B (1981) Secondary plant metabolism. Macmillan Press, London. 330p. 